Article

\title{
Vesicular-Bound HLA-G as a Predictive Marker for Disease Progression in Epithelial Ovarian Cancer
}

\author{
Esther Schwich ${ }^{1}$, Vera Rebmann ${ }^{1} * \mathbb{C}^{\mathbb{D}}$, Peter A. Horn ${ }^{1}$, Alexander A. Celik ${ }^{2}$, \\ Christina Bade-Döding ${ }^{2} \oplus$, Rainer Kimmig ${ }^{3}$, Sabine Kasimir-Bauer ${ }^{3}$ and Paul Buderath ${ }^{3}$ \\ 1 Institute for Transfusion Medicine, University Hospital Essen, University of Duisburg-Essen, \\ Virchowstr. 179, 45147 Essen, Germany \\ 2 Institute for Transfusion Medicine, Hannover Medical School, Carl-Neuberg-Str. 1, \\ 30625 Hannover, Germany \\ 3 Department for Gynecology and Obstetrics, University Hospital Essen, University of Duisburg-Essen, \\ Hufelandstr. 55, 45147 Essen, Germany \\ * Correspondence: Vera.Rebmann@uk-essen.de; Tel.: +49-201-7234206
}

Received: 25 June 2019; Accepted: 1 August 2019; Published: 2 August 2019

check for updates

\begin{abstract}
Extracellular vesicles (EV) and their tumor-supporting cargos provide a promising translational potential in liquid biopsies for risk assessment of epithelial ovarian cancer (EOC) patients frequently relapsing, despite initial complete therapy responses. As the immune checkpoint molecule HLA-G, which is operative in immune-escape, can be released by EV, we evaluate the abundance of EV and its vesicular-bound amount of HLA-G (HLA- $\left.\mathrm{G}_{\mathrm{EV}}\right)$ as a biomarker in EOC. After enrichment of EV from plasma samples, we determined the EV particle number and amount of HLA- $\mathrm{G}_{\mathrm{EV}}$ by nanoparticle tracking analysis or ELISA. The association of results with the clinical status/outcome revealed that both, EV particle number and HLA-G $\mathrm{G}_{\mathrm{EV}}$ were significantly elevated in EOC patients, compared to healthy females. However, elevated levels of HLA- $\mathrm{G}_{\mathrm{EV}}$, but not EV numbers, were exclusively associated with a disadvantageous clinical status/outcome, including residual tumor, presence of circulating tumor cells, and disease progression. High HLA-G $\mathrm{G}_{\mathrm{EV}}$ status was an independent predictor of progression, besides residual tumor burden and platinum-sensitivity. Especially among patients without residual tumor burden or with platinum-sensitivity, HLA-G $\mathrm{G}_{\mathrm{EV}}$ identified patients with high risk of progression. Thus, this study highlights HLA-G $\mathrm{E}_{\mathrm{EV}}$ as a potential novel biomarker for risk assessment of EOC patients with a rather beneficial prognosis defined by platinum-sensitivity or lack of residual tumor burden.
\end{abstract}

Keywords: extracellular vesicles; vesicular-bound HLA-G; HLA-G $\mathrm{EV}_{\mathrm{EV}}$; epithelial ovarian cancer (EOC); liquid biopsy; platinum therapy; residual tumor burden; circulating tumor cells

\section{Introduction}

Epithelial ovarian cancer (EOC) is the most lethal gynecologic malignancy [1]. According to the International Federation of Gynecology and Obstetrics (FIGO), it is classified into four surgical stages considering the extent of ovary affection and the extent of spreading outside the ovaries and outside the pelvis [1]. Primary treatment of EOC consists of cytoreductive surgery followed by adjuvant, platinum-based chemotherapy. Although initially responding to the primary treatment, tumor regrowth with a drug-resistant phenotype is frequent, resulting in an impaired overall survival [2]. Biomarkers predicting therapy response and prognosis in EOC are, therefore, desperately needed. In this context, circulating tumor cells (CTC) in the peripheral blood of EOC patients have been studied extensively, and their prognostic significance has been clearly shown [3]. However, although CTC have been well characterized in EOC patients $[4,5]$, it seems that they preferentially interact with other components 
of their environment to promote metastases than being solely responsible for metastasis formation. In breast cancer, we recently demonstrated a relationship, as well as a prognostic impact of CTC and circulating extracellular vesicles (EV) after neoadjuvant chemotherapy [6].

EV are membrane-surrounded structures released into the extracellular space by both healthy cells (e.g., trophoblasts and adult and embryonic stem cells [7]) and transformed cells, including breast cancer cells $[6,8]$, melanoma $[9,10]$, and renal cancer cells $[11,12]$. The generic term EV comprises lipoproteic vesicles of different sizes, origin, and composition, such as exosomes, microvesicles, and apoptotic bodies, making EV a very heterogeneous population $[10,13]$. EV are transported outside the producing cell and carry proteins, lipids, and nucleic acids characteristic of their cell of origin, being present either on the vesicle membrane or inside the vesicles [14]. As important cell-cell-communication mediators, they have been discussed to promote tumor initiation, metastasis formation, and therapy-resistance in cancer cells [15]. Thus, in the era of liquid biopsy, EV bear great translational potential for disease monitoring and prediction of therapy response and outcome in various malignancies [16-20].

Of note, high levels of EV [6] and high levels of a EV sub-population expressing the non-classical human leukocyte antigen-G (HLA-G) [21] have been associated with the failure of neoadjuvant chemotherapy and disease-progression in peripheral blood of locally advanced, primary breast cancer patients.

HLA-G is an immune checkpoint molecule regulating immune effector responses. It interacts with the immune-inhibitory receptors immunoglobulin-like transcript- (ILT-)2, ILT-4, and killer-cell immunoglobulin-like receptor (KIR)2DL4, expressed on different immune-competent cells [22]. Thus, HLA-G is associated with anti-inflammatory and immune-modulatory properties. HLA-G can be expressed at the cell surface (HLA-G1, -G2, -G3, and -G4) [23] or as soluble HLA-G forms, including secreted molecules (HLA-G5, -G6, and -G7) [24], shed molecules from the surface [25], or as released molecules by extracellular vesicles $[22,26]$. HLA-G is confined to the maternal-fetal interface and to immune-privileged adult tissues under physiological conditions [27], whereas neo-ectopic or aberrant expression of HLA-G and its soluble forms have been associated with a variety of pathological situations [28]. For instance, HLA-G and its soluble forms enable escape from host immune surveillance by inhibiting $\mathrm{B}$ cells, $\mathrm{T}$ cells, and natural killer cells and by inducing regulatory $\mathrm{T}$ cells [28-30], thereby mediating cancer invasiveness and metastatic progression [31]. There is evidence that HLA-G-bearing EV are an especially crucial factor in immune-tolerance mechanisms operative in malignant diseases [21,22], as the total amount of soluble HLA-G has not been associated with disease progression and overall survival in breast cancer patients.

With respect to EOC, the prognostic significance of HLA-G and soluble HLA-G expression is controversially debated, especially in view of a recent study demonstrating elevated soluble HLA-G levels and high HLA-G tissue expression being associated with an improved prognosis [32]. Our group could confirm increased levels of total soluble HLA-G, however, this was not associated with the nodal status, metastasis formation, presence of circulating or disseminated tumor cells prior to therapy and overall (OS), and progression-free survival (PFS) [33].

So far, the clinical importance of EV and of HLA-G-bearing EV in EOC remains unclear. In this retrospective study, we, therefore, enriched EV derived from plasma samples of primary, serous EOC patients by ExoQuick ${ }^{\mathrm{TM}}$ precipitation $[6,21]$ and quantified the EV preparations (i) for amount of total EV particle number, (ii) amount of vesicular-bound HLA-G (HLA-G $\mathrm{G}_{\mathrm{EV}}$ ), and (iii) related the results to clinical parameters, presence of CTCs, and disease outcome.

\section{Results}

\subsection{Characterization of Extracellular Vesicles in Plasma of EOC Patients and Healthy Controls}

EV preparations were analyzed for the presence of typical EV markers, including tetraspanin CD63, TSG101, and Syntenin, as well as the absence of Cytochrome C, as previously recommended [34] as a minimal requirement for the definition of EV, by SDS-PAGE and specific immunoblotting $[6,21]$ 
for four healthy controls (HC) and four EOC patients (Figure 1A). All preparations showed the typical EV marker profile. Additionally, NTA measurements showed a size distribution (mean $\pm \mathrm{SD} \mathrm{nm}$ ) of $125.6 \pm 9.2$ for EV detected in EOC patients and 123.5 \pm 8.1 for HC (Figure 1B), which corresponds to the known size of EV, ranging between 30-150 nm [13]. Both the EV marker analysis and the NTA results indicate that ExoQuick ${ }^{\mathrm{TM}}$ precipitation successfully enriched EV from the plasma samples.

A

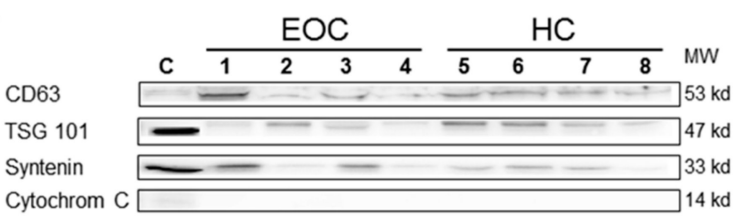

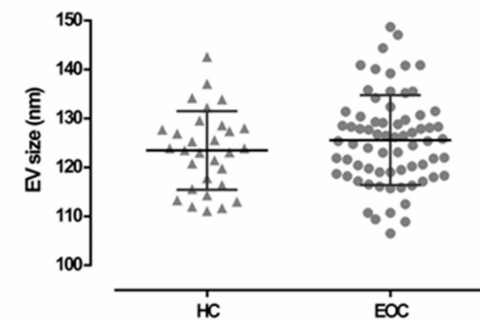

D

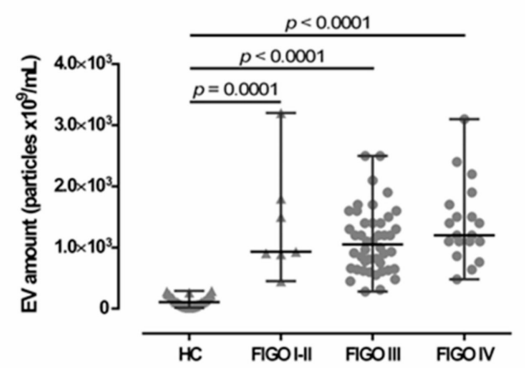

C

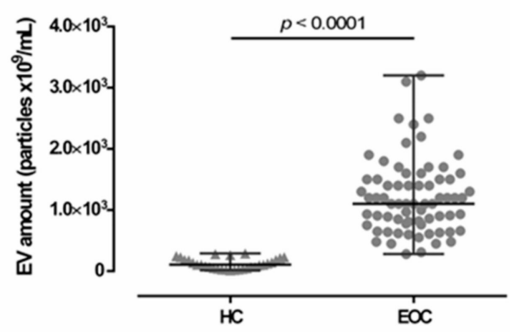

E

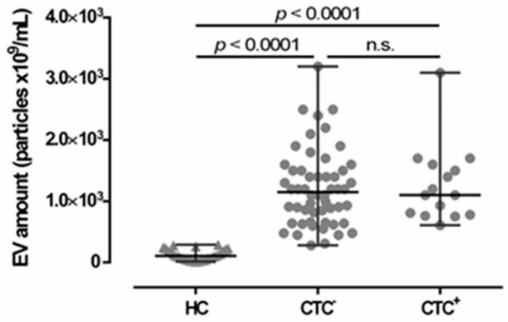

Figure 1. Comparison between extracellular vesicle (EV) preparations derived from plasma of epithelial ovarian cancer (EOC) patients and of healthy controls (HC). (A) Representative EV marker expression analysis for CD63, Tsg101, syntenin, and Cytochrome C in EV preparations from EOC patients (1-4) and four HC (5-8). Cell lysate of HEK G1 cells served as control. Detailed information can be found in Figure S1. (B) EV size analysis determined by nanoparticle tracking analysis revealed that EV size is similar in both HC and EOC patients. The mean \pm SD is given. (C) The EV amount was determined by NTA and showed that EOC patients harbor significantly higher amounts of EV, compared to HC. (D,E) Stratification of EV amount with regards to the International Federation of Gynecology and Obstetrics (FIGO) staging and presence of circulating tumor cells (CTC) showed enhanced EV amounts among all FIGO stages and irrespective of CTC status compared to HC. Given is the median with range. Statistical significance was tested by Mann-Whitney test (B,C) and Kruskal-Wallis test (D,E), $p<0.05$. n.s., not significant. Triangular symbols represent healthy controls, while round circular symbols illustrate EOC patients.

\subsection{Elevated Levels of Extracellular Vesicles in Serous EOC Patients}

Levels of EV (median [range] $10^{9} / \mathrm{mL}$ ) were determined in plasma samples from EOC patients $(n=70)$ and compared to those of HC $(n=30)$ by NTA (Figure 1C). EV particle concentration in EOC samples (1100 [280-3200]) was more than 10-fold elevated, compared to HC ((106.8 [14.3-289]), $p<0.0001)$. Stratification of patients according to FIGO staging revealed that EV levels were significantly elevated compared to HC (FIGO I-II ((930 [450-3200]), $p=0.0001$; FIGO III (1050 [280-2500]), $p<0.0001$; FIGO IV (1200 [480-3100]), $p<0.0001)$ independent of the extent of disease (Figure 1D). Further, EV levels were significantly elevated in both, patients without CTC before therapy ((1150 [280-3200]), 
$p<0.0001)$ and patients with CTC before therapy ((1100 [610-3100]), $p<0.0001)$, compared to HC (Figure 1E), whereas the particle number did not differ between patients with and without CTC. Regarding CTC-subtypes, EV particle number was neither associated with EpCAM positive CTC $\left(\right.$ EpCAM $^{+}: 1100$ [610-3100] vs. EpCAM ${ }^{-}: 1150$ [280-3200]), nor with MUC positive CTC (MUC ${ }^{+}: 1100$ [750-1600] vs. MUC $^{-}: 1200$ [280-3200]).

\subsection{Increased Levels of $H L A-G_{E V}$ in Serous EOC Patients}

To further characterize the EV in EOC patients, we quantified HLA- $\mathrm{G}_{\mathrm{EV}}$ (median [range] ng/mL; Table 1) in plasma samples of serous EOC patients $(n=78)$ and compared the amounts to the HLA-G $\mathrm{EV}_{\mathrm{EV}}$ levels of $30 \mathrm{HC}$. Consistent with the total particle concentration, the median HLA-G $\mathrm{G}_{\mathrm{EV}}$ levels of EOC patients (14.3 [2.9-60.4]) were more than 7-fold increased, compared to HC (1.9 [0.0-25.0]; see Figure 2A). Of note, in 6 out of $30(20 \%) \mathrm{HC}$, no HLA-G $\mathrm{G}_{\mathrm{EV}}$ could be detected, whereas all EOC patients revealed substantial amounts of detectable HLA- $\mathrm{G}_{\mathrm{EV}}(p<0.00001)$. However, particle concentrations did not correlate with HLA-G $\mathrm{G}_{\mathrm{EV}}$ levels $(\mathrm{r}=-0.06 ; p=0.507, n=69)$.

Table 1. Patient characteristics at time of primary diagnosis.

\begin{tabular}{|c|c|c|c|c|}
\hline \multirow{2}{*}{\multicolumn{2}{|c|}{ Total }} & \multirow{2}{*}{$\begin{array}{c}\text { Total EV Amount * } \\
n=70(\%)\end{array}$} & \multicolumn{2}{|c|}{ HLA-G ${ }_{\mathrm{EV}}$} \\
\hline & & & $n=78(\%)$ & $\begin{array}{c}\text { Median [Range] } \\
\mathrm{ng} / \mathrm{mL}\end{array}$ \\
\hline \multicolumn{2}{|c|}{ Age } & Median: 67 (42-98) & Median: 67 (42-98) & \\
\hline \multirow{3}{*}{ FIGO stage } & I-II & $7(10 \%)$ & $7(9 \%)$ & $13.3[2.9-20.5]$ \\
\hline & III & $44(63 \%)$ & $49(63 \%)$ & $13.1[3.4-60.4]$ \\
\hline & IV & $19(27 \%)$ & $22(28 \%)$ & $19.5[4.5-44.9]$ \\
\hline \multirow{3}{*}{ Nodal status } & $\mathrm{N}_{0}$ & $16(23 \%)$ & $18(23 \%)$ & $12.9[2.9-36.7]$ \\
\hline & $\mathrm{N}_{1}$ & $32(46 \%)$ & $34(44 \%)$ & $13.6[3.4-44.9]$ \\
\hline & unknown & $22(31 \%)$ & $26(33 \%)$ & \\
\hline \multirow{2}{*}{$\begin{array}{l}\text { Metastases } \\
\text { formation }\end{array}$} & $\mathrm{M}_{0}$ & $51(73 \%)$ & $56(72 \%)$ & $13.1[2.9-60.4]$ \\
\hline & $\mathrm{M}_{1}$ & $19(27 \%)$ & $22(28 \%)$ & $19.5[4.5-44.9]$ \\
\hline \multirow{2}{*}{ Tumor grading } & I-II & $27(39 \%)$ & $30(38 \%)$ & $16.3[4.5-50.7]$ \\
\hline & III & $43(61 \%)$ & $48(62 \%)$ & $13.2[2.9-60.4]$ \\
\hline \multirow{2}{*}{ Residual tumor } & no & $34(49 \%)$ & $37(47 \%)$ & $12.7[2.9-43.7]$ \\
\hline & yes & $36(51 \%)$ & $41(53 \%)$ & $18.7[4.5-60.4]$ \\
\hline \multirow{3}{*}{ CTC before therapy } & negative & $54(77 \%)$ & $61(78 \%)$ & $13.1[2.9-60.4]$ \\
\hline & positive & $15(22 \%)$ & $16(21 \%)$ & $29.1[10.4-44.9]$ \\
\hline & unknown & $1(1 \%)$ & $1(1 \%)$ & \\
\hline \multirow{3}{*}{ CTC before therapy } & MUC negative & $61(88 \%)$ & $70(90 \%)$ & $13.6[2.9-60.4]$ \\
\hline & MUC positive & $8(11 \%)$ & $7(9 \%)$ & $39.6[12.2-44.9]$ \\
\hline & unknown & $1(1 \%)$ & $1(1 \%)$ & \\
\hline \multirow{3}{*}{ CTC before therapy } & EpCAM negative & $64(92 \%)$ & $73(94 \%)$ & $13.3[2.9-60.4]$ \\
\hline & EpCAM positive & $5(7 \%)$ & $4(5 \%)$ & 32.7 [15.8-44.9] \\
\hline & unknown & $1(1 \%)$ & $1(1 \%)$ & \\
\hline \multirow{3}{*}{ CTC after therapy } & negative & $17(24 \%)$ & $20(26 \%)$ & $12.8[5.3-47.8]$ \\
\hline & positive & $7(10 \%)$ & $7(9 \%)$ & $12.7[8.0-44.9]$ \\
\hline & unknown & $46(66 \%)$ & $51(65 \%)$ & \\
\hline \multirow{3}{*}{$\begin{array}{l}\text { DTCs before } \\
\text { therapy }\end{array}$} & negative & $40(57 \%)$ & $46(59 \%)$ & $13.6[2.9-50.7]$ \\
\hline & positive & $28(40 \%)$ & $30(38 \%)$ & $15.0[6.0-60.4]$ \\
\hline & unknown & $2(3 \%)$ & $2(3 \%)$ & \\
\hline \multirow{3}{*}{$\begin{array}{l}\text { Platinum-based } \\
\text { chemotherapy }\end{array}$} & no resistance & $48(69 \%)$ & $51(66 \%)$ & $13.3[2.9-60.4]$ \\
\hline & resistance & $9(13 \%)$ & $12(15 \%)$ & 15.5 [5.3-44.9] \\
\hline & unknown & $13(18 \%)$ & $15(19 \%)$ & \\
\hline
\end{tabular}


Table 1. Cont.

\begin{tabular}{|c|c|c|c|c|}
\hline & \multirow[b]{2}{*}{ Total } & \multirow{2}{*}{$\begin{array}{c}\text { Total EV Amount * } \\
n=70(\%)\end{array}$} & \multicolumn{2}{|c|}{ HLA-G ${ }_{E V}$} \\
\hline & & & $n=78(\%)$ & $\begin{array}{c}\text { Median [Range] } \\
\mathrm{ng} / \mathrm{mL}\end{array}$ \\
\hline \multicolumn{2}{|c|}{ Age } & Median: 67 (42-98) & Median: 67 (42-98) & \\
\hline \multirow{3}{*}{ Recurrence (10y) } & no relapse & $23(33 \%)$ & $24(31 \%)$ & $13.2[3.4-50.7]$ \\
\hline & relapse & $46(66 \%)$ & $53(68 \%)$ & $16.8[2.9-60.4]$ \\
\hline & unknown & $1(1 \%)$ & $1(1 \%)$ & \\
\hline \multirow{3}{*}{$\begin{array}{l}\text { Overall Survival } \\
\qquad(10 \mathrm{y})\end{array}$} & alive & $38(54 \%)$ & $41(53 \%)$ & $13.1[2.9-60.40]$ \\
\hline & dead & $31(45 \%)$ & $36(46 \%)$ & $17.0[4.5-44.9]$ \\
\hline & unknown & $1(1 \%)$ & $1(1 \%)$ & \\
\hline
\end{tabular}

CTC—circulating tumor cell; DTCs—disseminated tumor cells; FIGO—Federation of Gynecology and Obstetrics; $\mathrm{M}_{0}$-no metastasis formation; $\mathrm{M}_{1}$-metastasis formation; $\mathrm{pN}_{0}$-no nodal infestation; $\mathrm{pN}_{1}$ 一nodal infestation; * $\mathrm{EV}$ particle could not be obtained for all patients.

A

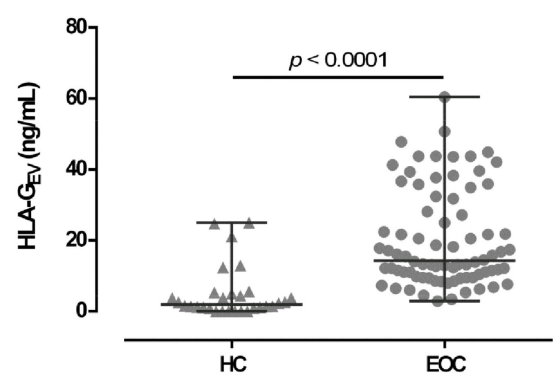

C

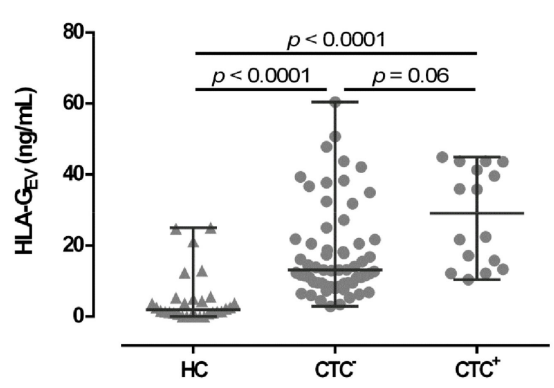

B

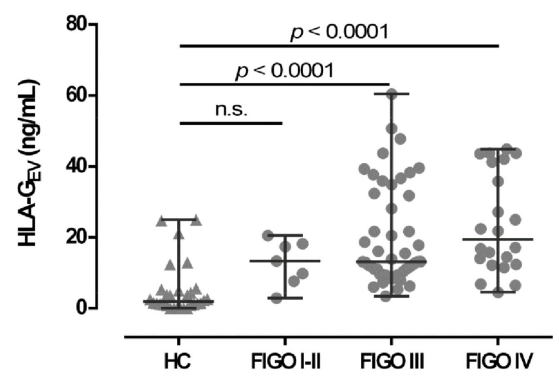

Figure 2. Association of HLA-G $\mathrm{G}_{\mathrm{EV}}$ levels of EOC patients, in comparison to HC. (A) HLA-G $\mathrm{G}_{\mathrm{EV}}$ levels are significantly increased in EOC patients, compared to HC. (B) Levels of HLA-G $\mathrm{GV}_{\mathrm{EV}}$ are increased in advanced FIGO stages. (C) EOC patients with detectable CTC harbor higher HLA-G $\mathrm{EV}_{\mathrm{EV}}$ levels, compared to HC and patients without CTC. Given is the median with range. Statistical significance was tested by Mann-Whitney test (A) and Kruskal-Wallis test (B,C), $p<0.05$. n.s., not significant. Triangular symbols represent healthy controls, while round circular symbols illustrate EOC patients.

\subsection{Elevated Levels of HLA-G $G_{E V}$ Associate with a Detrimental Clinical Profile of Serous EOC Patients}

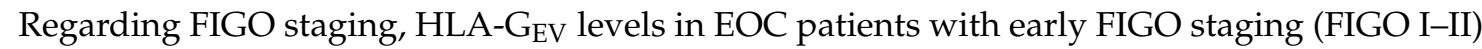
were not significantly elevated (13.3 [2.9-20.5]), compared to HC. However, HLA-G $\mathrm{EVV}_{\mathrm{EV}}$ levels of patients with advanced FIGO stages (FIGO III: 13.1 [3.4-60.4] and FIGO IV: 19.5 [4.5-44.9]) were significantly $(p<0.0001$ ) elevated (Figure 2B), compared to HC.

Due to the tumor-supporting features of HLA-G, we further analyzed the association of HLA-G $\mathrm{GV}_{\mathrm{EV}}$ with the presence of CTCs before therapy (Figure 2C). Compared to HC, HLA-G $\mathrm{G}_{\mathrm{EV}}$ levels were increased in patients with CTC (29.1 [10.4-44.9]; $p<0.0001)$ and in patients without CTC (13.1 [2.9-60.4], 
$p<0.0001)$. CTC positive patients showed more than 2-fold higher amounts of vesicular-bound HLA-G $(p=0.06)$ than CTC negative ones.

Concerning CTC specificity, HLA- $\mathrm{G}_{\mathrm{EV}}$ was significantly $(p=0.03)$ higher in patients with MUC positive CTC (39.6 [12.2-44.9]), compared to patients with MUC negative CTC (13.6 [2.9-60.4]; Figure $3 A$ ) with a 3-fold increase in the median HLA-G ${ }_{E V}$ levels. Similar, high HLA-G $G_{E V}$ levels were associated $(p=0.05)$ with EpCAM positive CTC (32.7 [15.8-44.9]), compared to EpCAM negative CTC (13.3 [2.9-60.4]; Figure 3B).

A

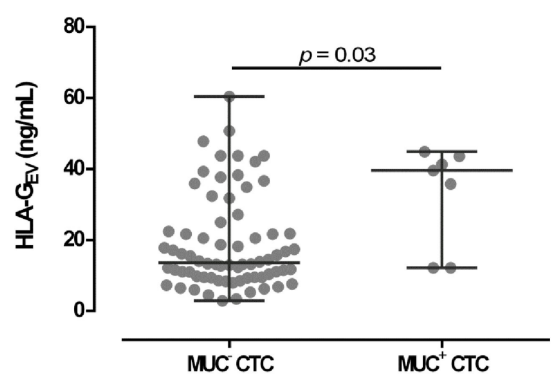

C

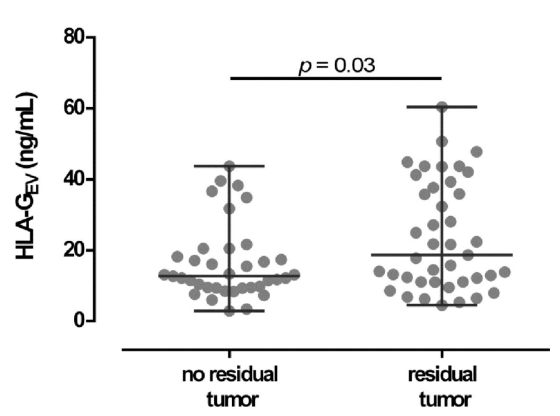

B

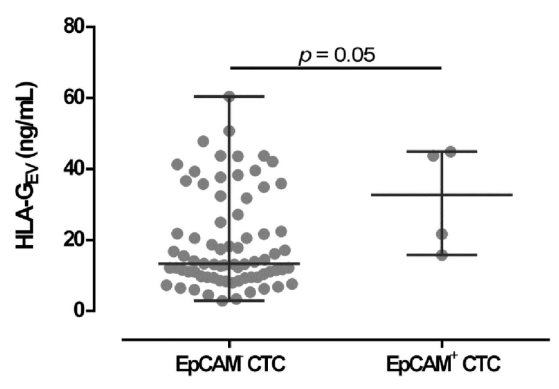

Figure 3. Association between HLA-G $G_{\mathrm{EV}}$ levels with clinical parameters in EOC patients. (A,B) Levels of HLA-G $G_{E V}$ are elevated in both patients with MUC and EpCAM positive CTC, compared to patients carrying MUC or EpCAM negative CTC. Given is the median [range] in $\mathrm{ng} / \mathrm{mL}$. Statistical significance was tested by Mann-Whitney test, $p<0.05$. (C) HLA- $\mathrm{G}_{\mathrm{EV}}$ levels were higher in EOC patients with a residual tumor burden compared to patients without a detectable residual tumor. Statistical significance was tested by Mann-Whitney test, $p<0.05$.

Considering residual tumor burden, levels of HLA-G $\mathrm{G}_{\mathrm{EV}}$ were significantly $(p=0.03)$ elevated (18.7 [4.5-60.4]) in patients with a detectable residual tumor after primary surgery, compared to patients without a residual tumor burden (12.7 [2.9-43.7]; Figure 3C).

\subsection{HLA-G $G_{E V}$ Status as a Prognostic Marker for the Prediction of Disease Progression in EOC Patients}

Receiver operating curve analysis was used to define the optimal cut-off value for risk assessment regarding disease progression in EOC patients. Using the obtained cut-off value of $18.45 \mathrm{ng} / \mathrm{mL}$ HLA-G $\mathrm{G}_{\mathrm{EV}}$ (sensitivity: $46.9 \%$, specificity: $77.8 \%$ ), $n=30$ patients were identified with levels higher than $18.45 \mathrm{ng} / \mathrm{mL}$, whereas $n=48$ patients had lower levels. Kaplan-Meier curve analysis combined with log-rank test showed that EOC patients with HLA-G $\mathrm{G}_{\mathrm{EV}}$ status $>18.45 \mathrm{ng} / \mathrm{mL}$ had a significantly $(p=0.029)$ reduced 3-year progression-free survival (PFS) with a median PFS time of $15 \pm 2.5$ months (HR: 1.8, 95\% CI: 1.1-3.6), compared to EOC patients with a low HLA-G $\mathrm{GV}_{\mathrm{EV}}$ status with a median PFS time of $29 \pm 7.1$ months (Figure $4 \mathrm{~A}$ ). 
A Progression-Free Survival (PFS)
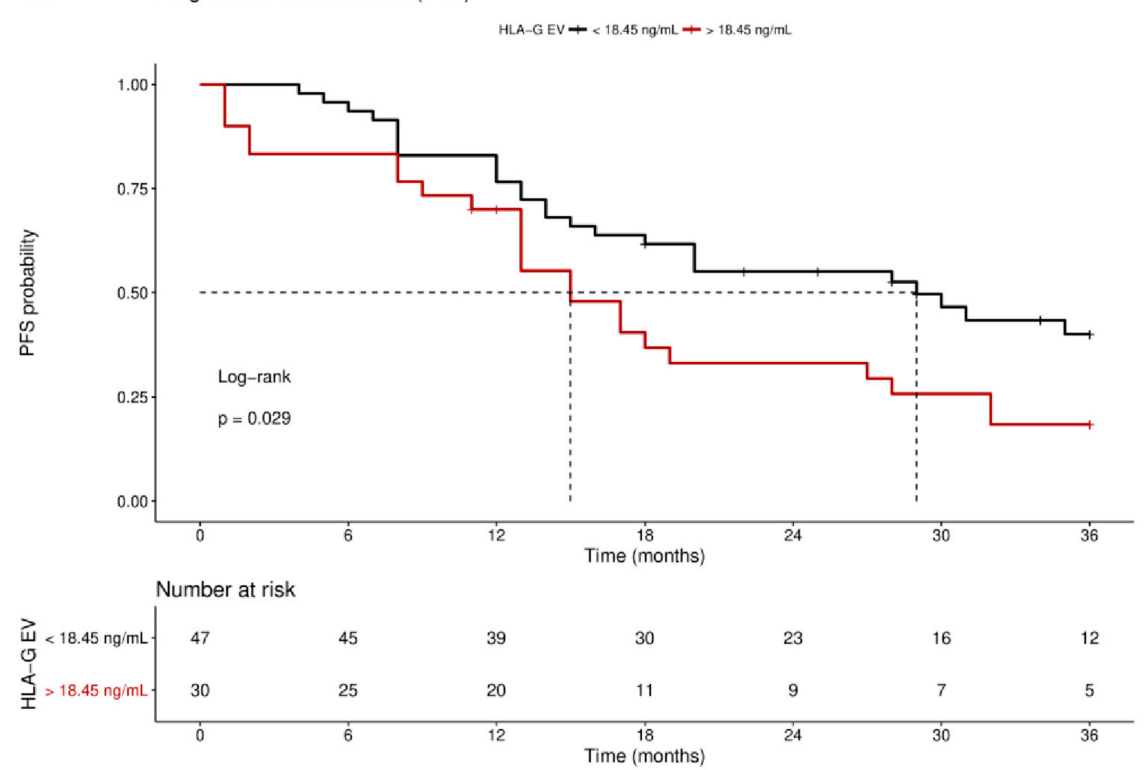

B PFS of patients sensitive to platinum therapy HLA-G EV $+<18.45 \mathrm{ng} / \mathrm{mL} \rightarrow>18.45 \mathrm{ng} / \mathrm{mL}$
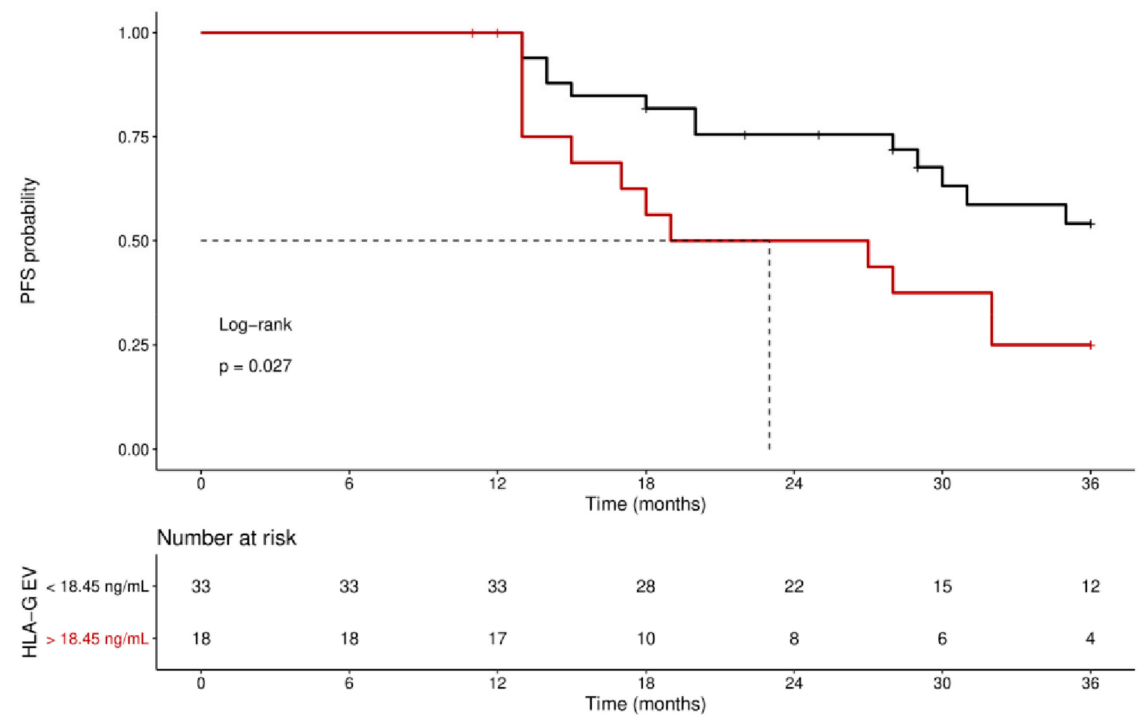

Figure 4. Kaplan-Meier survival analysis regarding vesicular-bound HLA-G. Kaplan-Meier analysis combined with log-rank test revealed that high levels of HLA- $\mathrm{G}_{\mathrm{EV}}$ are associated (A) with a significantly reduced 3-year PFS, and (B) with an inferior 3-year PFS in patients sensitive to platinum therapy. The red line indicates patients with HLA- $\mathrm{G}_{\mathrm{EV}}$ levels greater than $18.45 \mathrm{ng} / \mathrm{mL}$, whereas the black line illustrates patients with HLA-G $\mathrm{G}_{\mathrm{EV}}$ levels less than $18.45 \mathrm{ng} / \mathrm{mL}$. The dotted lines reveal the median survival time, where applicable. Tables under Kaplan-Meier plots show the corresponding numbers at risk.

Multivariate analysis, including metastasis and nodal status, presence of CTC before therapy, residual tumor burden, platinum therapy sensitivity, and HLA- $\mathrm{G}_{\mathrm{EV}}$ level status, was performed. Strikingly, platinum therapy sensitivity $(p<0.0001$ and $p<0.0001)$, residual tumor burden $(p=0.023$ and $p=0.011)$, and elevated HLA-G $\mathrm{G}_{\mathrm{EV}}(p=0.029$ and $p=0.006)$ were shown to be independent prognostic factors for both 3-year and 10-year PFS, respectively, whereas presence of CTC before therapy did not reach significance ( $p=0.101$ and $p=0.08$; Table 2). Analogous univariate and multivariate evaluations of the OS revealed no association with HLA-G $\mathrm{GVV}_{\mathrm{EV}}$ status. 
Table 2. Multivariate analysis to predict disease progression in EOC patients.

\begin{tabular}{|c|c|c|c|c|c|c|}
\hline \multicolumn{2}{|l|}{ Risk Factors } & \multirow{3}{*}{$\begin{array}{c}n \\
34 \\
10\end{array}$} & \multicolumn{2}{|c|}{ 3-Year PFS } & \multicolumn{2}{|c|}{ 10-Year PFS } \\
\hline & & & $p$ & HR $(95 \%$ CI) & $p$ & HR $(95 \% \mathrm{CI})$ \\
\hline Metastasis & $\begin{array}{l}\mathrm{M}_{0} \\
\mathrm{M}_{1}\end{array}$ & & 0.467 & $1.7(0.4-7.7)$ & 0.351 & $2.0(0.5-9.0)$ \\
\hline Nodal status & $\begin{array}{l}\mathrm{N}_{0} \\
\mathrm{~N}_{1}\end{array}$ & $\begin{array}{l}16 \\
28\end{array}$ & 0.858 & $1.1(0.4-3.2)$ & 0.819 & $0.9(0.3-2.4)$ \\
\hline CTC before therapy & $\begin{array}{l}\text { negative } \\
\text { positive }\end{array}$ & $\begin{array}{c}36 \\
8\end{array}$ & 0.101 & $2.8(0.8-9.7)$ & 0.08 & $3.0(0.9-10.0)$ \\
\hline Residual tumor burden & $\begin{array}{l}\text { yes } \\
\text { no }\end{array}$ & $\begin{array}{l}13 \\
31\end{array}$ & 0.023 & $2.9(1.2-7.4)$ & 0.011 & $3.3(1.3-8.4)$ \\
\hline Platinum-based chemotherapy & $\begin{array}{l}\text { no resistance } \\
\text { resistance }\end{array}$ & $\begin{array}{c}36 \\
8\end{array}$ & $<0.0001$ & $16.4(4.5-59.2)$ & $<0.0001$ & $\begin{array}{c}28.8 \\
(6.4-130.0)\end{array}$ \\
\hline HLA-G $\mathrm{G}_{\mathrm{EV}}$ status & $\begin{array}{l}<18.45 \mathrm{ng} / \mathrm{mL} \\
>18.45 \mathrm{ng} / \mathrm{mL}\end{array}$ & $\begin{array}{l}33 \\
11\end{array}$ & 0.029 & $2.9(1.1-7.6)$ & 0.006 & $3.8(1.5-9.9)$ \\
\hline
\end{tabular}

As response to platinum therapy and the residual tumor burden are critical factors for the prediction of disease progression, we further stratified the patients according to these parameters. For patients sensitive to platinum therapy $(n=51)$, Kaplan-Meier analysis showed that high HLA-G $\mathrm{EV}_{\mathrm{EV}}$ status was significantly $(p=0.027)$ associated with a reduced 3-year PFS, with a median PFS of $23 \pm 9$ months (HR: 2.3, 95\% CI: 1.1-6.5), compared to a low level status with an undefined PFS time (Figure 4B). Similarly, EOC patients with no residual tumor burden $(n=37)$ and high levels status $(n=9)$ exhibited a reduced 3-year PFS (HR: 2.5, 95\% CI: 1.1-9.3, $p=0.04$, Figure S2).

For the long-term observation of disease progression of patients with no residual tumor burden, it became evident that a high status was significantly $(p=0.018)$ associated with an inferior 10-year PFS, with a median survival time of $27 \pm 13.4$ month (HR: 2.7, 95\% CI: 1.3-10.1; Figure 5), compared to a low status of vesicular-bound HLA-G with a median survival time of $68 \pm 25.6$ months. Of note, all patients with high HLA- $\mathrm{G}_{\mathrm{EV}}(n=9)$ status experienced disease progression within approximately 5 years after primary diagnosis.

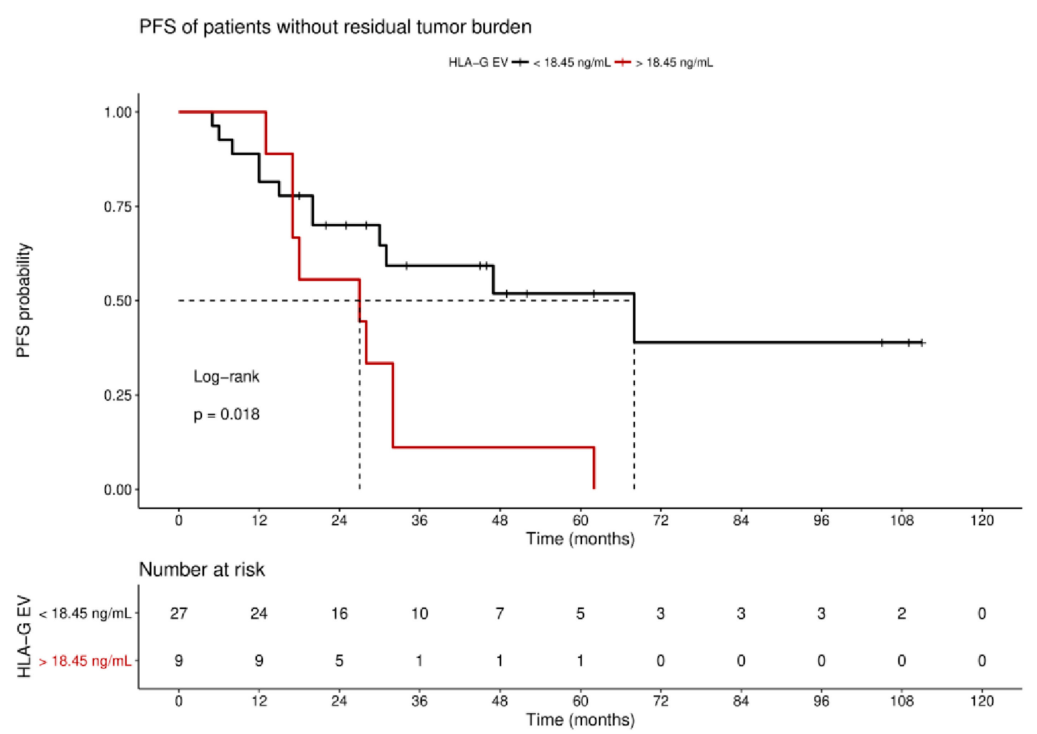

Figure 5. Kaplan-Meier survival analysis regarding HLA-G $\mathrm{G}_{\mathrm{EV}}$ status for patients without residual tumor burden. Kaplan-Meier analysis combined with log-rank test demonstrated that high levels of HLA-G $G_{E V}$ are significantly associated with a reduced 10-year PFS in patients without residual tumor burden. The red line represents patients with $H L A-G_{E V}$ levels greater than $18.45 \mathrm{ng} / \mathrm{mL}$, whereas the black line illustrates patients with HLA-G $\mathrm{G}_{\mathrm{EV}}$ levels less than $18.45 \mathrm{ng} / \mathrm{mL}$. The dotted lines indicate median survival time. Tables under Kaplan-Meier plots show the corresponding numbers at risk. 
Concerning patients resistant to platinum therapy or patients with a residual tumor, an association with HLA- $\mathrm{G}_{\mathrm{EV}}$ levels was found in neither of the univariate or multivariate analyses. Thus, HLA-G $\mathrm{EV}_{\mathrm{EV}}$ status seems to be a promising factor for the prediction of disease recurrence, in particular for patients considered as low risk patients for disease progression due to their sensitivity to platinum therapy and lack of residual tumor.

\section{Discussion}

EV provide a promising translational potential in the context of malignancies. Both the rate of EV release, as well as the EV-mediated transfer of different cargos, represent novel strategies for disease monitoring [20]. Although the immune checkpoint molecule HLA-G has been associated with cancer invasiveness and metastatic spread in various malignant diseases [35,36], we were not able to correlate the total amount of sHLA-G to the clinical status or outcome of EOC patients in a previous study [33]. Of note, sHLA-G can also be released by EV, which has been proposed to play an important role in the immune-tolerance mechanisms in different malignant diseases [22]. Thus, we hypothesized that overall EV abundance, as well as amounts of vesicular-bound HLA-G, reflects the disease status and outcome of EOC patients. In our study, we could demonstrate that (i) levels of plasma EV in EOC patients were elevated more than 10-fold, compared to HC, (ii) levels of HLA- $\mathrm{G}_{\mathrm{EV}}$ were more than 7-fold increased in EOC patients, compared to HC, (iii) elevated HLA-G $\mathrm{EV}_{\mathrm{EV}}$ levels were associated with an inferior clinical status and outcome regarding residual tumor, presence of CTC, and PFS, that (iv) HLA- $\mathrm{G}_{\mathrm{EV}}$ status served as an independent marker for risk assessment of disease progression, and, lastly, (v) among patients without residual tumor burden or with platinum-sensitivity, HLA-G identified patients with a high risk of progression.

The characterization of EV enriched from EOC patient samples was performed according to the current recommendations [34]. We detected the tetraspanin-specific marker CD63, as well as the escort complex associated markers Tsg101 and Syntenin, in all EV preparations. Varying amounts might be due to the different composition of EV sources, which is in concordance with previous studies [6,21]. Cellular contamination was excluded by the intercellular protein cytochrome $\mathrm{C}$, which was not detected in the EV preparations.

Although a clear discrimination between physiological and pathological EV serum levels could be obtained, increased EV levels were independent of the FIGO staging or the CTC status and, thus, cannot be used to discriminate the clinical profile of EOC patients.

Stratification of EV regarding their HLA-G content revealed that HLA-G $\mathrm{GV}_{\mathrm{EV}}$ could not be detected at all in some healthy donors, whereas levels increased with advanced cancer stages in EOC. This suggests an association between the amount of HLA- $\mathrm{G}_{\mathrm{EV}}$ and the tumor burden. Neo-ectopic expression of HLA-G as a vesicular form can be considered as a critical factor for cancer progression. Indeed, patients with high levels of HLA-G $\mathrm{EV}_{\mathrm{EV}}$ had a reduced PFS, pointing to the notion that HLA-G-bearing EV facilitate or support tumor escape from the immune system. This concept is further supported by the association of HLA-G and CTC status before therapy: Levels of HLA-G $\mathrm{EVV}_{\mathrm{EV}}$ were elevated in patients positive for CTC, compared to patients without CTC. As CTC are malignant cells released by tumor tissues undergoing epithelial-mesenchymal transition, while EV are released by both malignant and nonmalignant cells, EV signals may originate not only from the tumor-derived EV, but also from EV secreted by other cells, such as immune cells [19]. Similarly, it has already been demonstrated that soluble HLA-G can be derived from different cell sources [37,38]. Of note, CTC themselves exploit a large variety of immune-escape mechanisms, including aberrant expression of immune checkpoint molecules (e.g., FASL or PD-L1) [39]. HLA-G bearing EV derived from renal cancer stem-cells were shown to induce the inhibition of dendritic cell differentiation, thereby modifying immune responses towards tumor cells [40]. Independent of the source of vesicular HLA-G, the presence of HLA-G seems to render (tumor) cells immunologically invisible by transducing inhibitory signals towards effector cells promoting cancer progression. Interestingly, we determined an association between high HLA-G $\mathrm{G}_{\mathrm{EV}}$ levels and MUC or EpCAM positive CTC, both being related to poor clinical outcomes in 
malignancies [41-43]. Thus, presence of CTC and HLA- $\mathrm{G}_{\mathrm{EV}}$ might represent different manifestations of the same phenomenon, suggesting a more 'immunosuppressive' subtype of EOC, which is clinically present with higher stages. Nevertheless, this observation should be validated in a cohort encompassing more CTC positive EOC patients. Concerning immunotherapeutic approaches to eliminate single tumor cells in blood and bone marrow, we have been able to show that the application of the intraperitoneal trifunctional bispecific antibody catumaxumab was successful in advanced EOC [44]. For HLA-G $\mathrm{GV}_{\mathrm{EV}}$ it would be desirable to develop therapeutic options, either preventing release of HLA-G bearing EV or neutralizing functionality of HLA-G by, for example, receptor blockade.

Although HLA- $\mathrm{G}_{\mathrm{EV}}$ status does not have a prognostic relevance for patients resistant to platinum therapy, it allows discrimination of patients responding to platinum therapy: Patients with higher levels of HLA-G $\mathrm{G}_{\mathrm{EV}}$ had an inferior PFS, compared to patients with lower levels, suggesting that HLA- $\mathrm{G}_{\mathrm{EV}}$ might act as a mediator of tumor recurrence despite initial treatment response.

In addition, besides platinum sensitivity, residual tumor burden after primary debulking surgery is one of the most important prognostic factors in EOC [44]. Nevertheless, despite macroscopic complete tumor resection, patients experienced disease recurrence within three years in our cohort. According to our results, stratification of these patients based on the HLA-G $\mathrm{EVV}_{\mathrm{EV}}$ status might help to identify patients at risk for disease progression. Indeed, the HLA- $\mathrm{G}_{\mathrm{EV}}$ status was found to be an independent predictive parameter besides platinum sensitivity and presence of CTC before therapy.

Although our study had several limitations, mostly due to the small sample size and its retrospective nature, the clinical relevance of our findings is especially of interest for patients with a rather good prognosis, as defined by sensitivity to platinum therapy and/or no residual tumor burden. As of now, prediction of post-operative outcome is still difficult and clinical examination, as well as imaging techniques, still do not allow for a sufficient prediction of disease recurrence. Thus, risk assessment with additional parameters and novel individualized therapy concepts are urgently needed for patients with a rather good prognosis. Here, HLA- $\mathrm{G}_{\mathrm{EV}}$ might be a promising candidate as a biomarker easily accessible through liquid biopsy, guiding the development and establishment of individualized therapy concepts. Nevertheless, further research will have to elucidate the prognostic significance of HLA- $\mathrm{G}_{\mathrm{EV}}$ status and its possible role as a prognostic and predictive biomarker in EOC.

\section{Materials and Methods}

\subsection{Patient Characteristics}

Our cohort consisted of 78 patients diagnosed with histologically confirmed EOC between 2001 and 2014 at the Department of Gynecology and Obstetrics, University Hospital Essen. Tumor classification followed the WHO classification of tumors of the female genital tract. Grading was conducted using the grading system proposed by Silverberg and tumor staging was classified according to the Fédération Internationale de Gynécology et d'Obstétrique (FIGO). All patients underwent primary radical surgery including abdominal hysterectomy, bilateral salpingo-oophorectomy, infragastric omentectomy, peritoneal stripping, and systematic pelvic and paraaortic lymphadenectomy, if indicated. All patients received at least six cycles of carboplatinum AUC 5 and paclitaxel $175 \mathrm{mg} / \mathrm{m}^{2}$. Tumors were defined as platinum-resistant if they recurred within six months after the completion of the adjuvant platinum treatment. Any macroscopic residual disease at the end of primary surgery was defined as 'residual tumor'. Inclusion criteria were: Histologically confirmed EOC, primary radical surgery, platinum-based chemotherapy, and availability of serum-samples and follow-up information. All patients from the selected time period who met these criteria were included. Chemotherapy was administered post-operatively in all patients during this period. Clinical characteristics of the patients are documented in Table 1. A total of 30 healthy female donors served as controls. Written informed consent was obtained by all participants and the study was approved by the Local Ethics Committee (Essen 05-2870 and 17-7859) and was performed according to the declaration of Helsinki. Patient characteristics at time of primary diagnosis are summarized in Table 1. 


\subsection{Sampling of Blood}

At the time of primary diagnosis, prior to surgery, $10 \mathrm{~mL}$ ethylenediaminetetraacetic (EDTA) blood was collected for isolation of CTCs before the application of therapeutic substances with an S-Monovette (Sarstedt AG \& Co., Nürnbrecht, Germany) and stored at $4{ }^{\circ} \mathrm{C}$ until further examination. The samples were processed within $4 \mathrm{~h}$ after blood collection.

\subsection{Selection, Detection and Evaluation of CTCs}

AdnaTest OvarianCancer (QIAGEN, Hilden, Germany) was employed for enrichment of CTCs and subsequent expression analysis. This test has been described in detail $[4,45]$.

\subsection{Isolation of Extracellular Vesicles}

Plasmatic extracellular vesicles were isolated using ExoQuick ${ }^{\mathrm{TM}}$ (SBI Systems Bioscience Inc., Mountain View, VA, USA), as described previously [21].

\subsection{EV Characterization by Western Blot}

EV characterization by SDS-PAGE and western blot analysis was performed as previously described [21]. ExoQuick ${ }^{\mathrm{TM}}$ reagent was removed from EV suspensions by PD SpinTap G-25 (GE Healthcare, Freiburg, Germany) prior to SDS-PAGE and western blotting. EV suspensions (15 $\mu \mathrm{g}$ ) from four healthy controls and from four EOC patients were analyzed. Cell lysate derived from HEK G1 cells $(10 \mu \mathrm{g})$ served as control.

\subsection{Nanoparticle Tracking Analysis}

Particle number and size were analyzed using the ZetaView Laser Scattering Video Microscope (Particle Metrix GmbH, Meerbusch, Germany) and its corresponding software (version 8.03.08.02), as previously described [46].

\subsection{Quantification of Soluble HLA-G Components}

Soluble HLA-G was quantified, as previously described [21,47]. EV suspensions were used in a dilution of 1:2 in PBS and purified HLA-G1 [48] served as standard reagent. Soluble HLA-G levels were determined by four-parameter curve fitting. ELISA detection limit of HLA-G was $0.25 \mathrm{ng} / \mathrm{mL}$. HLA-G concentration in EV fractions was considered as HLA-G $\mathrm{GV}_{\mathrm{EV}}$.

\subsection{Statistical Analysis}

Statistical analysis was performed using SPSS 22.0 (SPSS Inc., Chicago, IL, USA) and the GraphPad Prism V6.0 software (GraphPad Software, San Diego, CA, USA). Except for particle size (mean \pm SD), all metric parameters were given as median and range. After testing for Gaussian distribution, data sets were analyzed using either the Mann-Whitney test or the Kruskal-Wallis test with Dunn's correction for multiple comparison. Receiver operating curve (ROC) analysis was performed to obtain a cut-off value in terms of sensitivity and specificity, using the BIAS 10.02 software program (http://www.biasonline.de/) for categorization of HLA-G $\mathrm{G}_{\mathrm{EV}}$ status. Progression-free survival (PFS) analyses were assessed by the method of Kaplan-Meier and compared using log-rank test, implemented in the R package survminer (version 0.4.0; https://CRAN.R-project.or/package=survminer). Starting points were time point of diagnosis (blood collection) and endpoint was progress or relapse of EOC disease (therapy requirement). Multivariate Cox regression according to proportional hazards assumption was used to assess the risk of progression.

\section{Conclusions}

In conclusion, our study highlights that a certain subset of EV with HLA- $G_{E V}$, but not the abundance of total EV, offer great clinical and prognostic potential in EOC patients. The molecular 
characterization of these EV will provide substantial information regarding course of disease and may facilitate individual patient risk management with novel therapy concepts in EOC patients; especially in patients with a rather good prognosis, as defined by sensitivity to platinum therapy or no residual tumor burden.

Supplementary Materials: The following are available online at http:/www.mdpi.com/2072-6694/11/8/1106/s1, Figure S1: Characterization of EV preparations by western blot, Figure S2: 3-year PFS Kaplan-Meier survival analysis regarding HLA- $\mathrm{G}_{\mathrm{EV}}$ status of patients without residual tumor burden.

Author Contributions: Conceptualization, E.S., V.R., S.K.-B. and P.B.; and methodology, E.S. and A.C.; validation, E.S., V.R., S.K.-B. and P.B.; formal analysis, E.S. and V.R.; investigation, E.S. and V.R.; resources, V.R., P.A.H. and C.B.-D.; clinical data curation, R.K., S.K.-B. and P.B.; writing-original draft preparation, E.S., V.R., S.K.-B. and P.B.; writing-review and editing, E.S., V.R., P.A.H., A.C., C.B.-D., R.K., S.K.-B. and P.B.; visualization, E.S.; supervision, V.R. and S.K.-B.; project administration, P.B. and S.K.-B.

Funding: We acknowledge support by the Open Access Publication Fund of the University of Duisburg-Essen.

Acknowledgments: We gratefully thank the patients and healthy controls for participation in the study and for kindly providing the samples. We highly value the technical support by the colleagues of the Institute for Transfusion Medicine, especially Sabine Schramm and Monika Collenburg, and the medical and laboratory team of the Department of Gynecology and Obstetrics (both University Hospital Essen). Special thanks go to Bernd Giebel for providing the NTA facility.

Conflicts of Interest: S. Kasimir-Bauer is a consultant for Qiagen. V. Rebmann declares research support and travel support from Bristol Myers Squibb. All other authors declare no potential conflicts of interest. The funders had no role in the design of the study; in the collection, analyses, or interpretation of data; in the writing of the manuscript, or in the decision to publish the results.

\section{References}

1. Jelovac, D.; Armstrong, D.K. Recent progress in the diagnosis and treatment of ovarian cancer. CA Cancer J. Clin. 2011, 61, 183-203. [CrossRef]

2. Housman, G.; Byler, S.; Heerboth, S.; Lapinska, K.; Longacre, M.; Snyder, N.; Sarkar, S. Drug resistance in cancer: An overview. Cancers (Basel) 2014, 6, 1769-1792. [CrossRef] [PubMed]

3. Giannopoulou, L.; Kasimir-Bauer, S.; Lianidou, E.S. Liquid biopsy in ovarian cancer: Recent advances on circulating tumor cells and circulating tumor DNA. Clin. Chem. Lab. Med. 2018, 56, 186-197. [CrossRef] [PubMed]

4. Chebouti, I.; Kuhlmann, J.D.; Buderath, P.; Weber, S.; Wimberger, P.; Bokeloh, Y.; Hauch, S.; Kimmig, R.; Kasimir-Bauer, S. ERCC1-expressing circulating tumor cells as a potential diagnostic tool for monitoring response to platinum-based chemotherapy and for predicting post-therapeutic outcome of ovarian cancer. Oncotarget 2017, 8, 24303-24313. [CrossRef] [PubMed]

5. Chebouti, I.; Kasimir-Bauer, S.; Buderath, P.; Wimberger, P.; Hauch, S.; Kimmig, R.; Kuhlmann, J.D. EMT-like circulating tumor cells in ovarian cancer patients are enriched by platinum-based chemotherapy. Oncotarget 2017, 8, 48820-48831. [CrossRef]

6. Konig, L.; Kasimir-Bauer, S.; Bittner, A.K.; Hoffmann, O.; Wagner, B.; Santos Manvailer, L.F.; Kimmig, R.; Horn, P.A.; Rebmann, V. Elevated levels of extracellular vesicles are associated with therapy failure and disease progression in breast cancer patients undergoing neoadjuvant chemotherapy. Oncoimmunology 2017, 7, e1376153. [CrossRef]

7. Yanez-Mo, M.; Siljander, P.R.; Andreu, Z.; Zavec, A.B.; Borras, F.E.; Buzas, E.I.; Buzas, K.; Casal, E.; Cappello, F.; Carvalho, J.; et al. Biological properties of extracellular vesicles and their physiological functions. J. Extracell. Vesicles 2015, 4, 27066. [CrossRef] [PubMed]

8. Muralidharan-Chari, V.; Clancy, J.; Plou, C.; Romao, M.; Chavrier, P.; Raposo, G.; D'Souza-Schorey, C. ARF6-regulated shedding of tumor cell-derived plasma membrane microvesicles. Curr. Biol. 2009, 19, 1875-1885. [CrossRef]

9. Hood, J.L.; San, R.S.; Wickline, S.A. Exosomes released by melanoma cells prepare sentinel lymph nodes for tumor metastasis. Cancer Res. 2011, 71, 3792-3801. [CrossRef]

10. Raposo, G.; Stoorvogel, W. Extracellular vesicles: Exosomes, microvesicles, and friends. J. Cell. Biol. 2013, 200, 373-383. [CrossRef] 
11. Van Balkom, B.W.; Pisitkun, T.; Verhaar, M.C.; Knepper, M.A. Exosomes and the kidney: Prospects for diagnosis and therapy of renal diseases. Kidney Int. 2011, 80, 1138-1145. [CrossRef] [PubMed]

12. Fang, D.Y.; King, H.W.; Li, J.Y.; Gleadle, J.M. Exosomes and the kidney: Blaming the messenger. Nephrology (Carlton) 2013, 18, 1-10. [CrossRef] [PubMed]

13. Gyorgy, B.; Szabo, T.G.; Pasztoi, M.; Pal, Z.; Misjak, P.; Aradi, B.; Laszlo, V.; Pallinger, E.; Pap, E.; Kittel, A.; et al. Membrane vesicles, current state-of-the-art: Emerging role of extracellular vesicles. Cell. Mol. Life Sci. 2011, 68, 2667-2688. [CrossRef] [PubMed]

14. Thery, C.; Zitvogel, L.; Amigorena, S. Exosomes: Composition, biogenesis and function. Nat. Rev. Immunol. 2002, 2, 569-579. [CrossRef] [PubMed]

15. Mashouri, L.; Yousefi, H.; Aref, A.R.; Ahadi, A.M.; Molaei, F.; Alahari, S.K. Exosomes: Composition, biogenesis, and mechanisms in cancer metastasis and drug resistance. Mol. Cancer 2019, 18, 75. [CrossRef] [PubMed]

16. Skog, J.; Wurdinger, T.; van Rijn, S.; Meijer, D.H.; Gainche, L.; Sena-Esteves, M.; Curry, W.T., Jr.; Carter, B.S.; Krichevsky, A.M.; Breakefield, X.O. Glioblastoma microvesicles transport RNA and proteins that promote tumour growth and provide diagnostic biomarkers. Nat. Cell. Biol. 2008, 10, 1470-1476. [CrossRef]

17. Nawaz, M.; Camussi, G.; Valadi, H.; Nazarenko, I.; Ekstrom, K.; Wang, X.; Principe, S.; Shah, N.; Ashraf, N.M.; Fatima, F.; et al. The emerging role of extracellular vesicles as biomarkers for urogenital cancers. Nat. Rev. Urol. 2014, 11, 688-701. [CrossRef]

18. Lin, J.; Li, J.; Huang, B.; Liu, J.; Chen, X.; Chen, X.M.; Xu, Y.M.; Huang, L.F.; Wang, X.Z. Exosomes: Novel biomarkers for clinical diagnosis. Sci. World J. 2015, 2015, 657086. [CrossRef]

19. Keup, C.; Mach, P.; Aktas, B.; Tewes, M.; Kolberg, H.C.; Hauch, S.; Sprenger-Haussels, M.; Kimmig, R.; Kasimir-Bauer, S. RNA Profiles of Circulating Tumor Cells and Extracellular Vesicles for Therapy Stratification of Metastatic Breast Cancer Patients. Clin. Chem. 2018, 64, 1054-1062. [CrossRef]

20. Schwich, E.; Rebmann, V. The Inner and Outer Qualities of Extracellular Vesicles for Translational Purposes in Breast Cancer. Front. Immunol. 2018, 9, 584. [CrossRef]

21. Konig, L.; Kasimir-Bauer, S.; Hoffmann, O.; Bittner, A.K.; Wagner, B.; Manvailer, L.F.; Schramm, S.; Bankfalvi, A.; Giebel, B.; Kimmig, R.; et al. The prognostic impact of soluble and vesicular HLA-G and its relationship to circulating tumor cells in neoadjuvant treated breast cancer patients. Hum. Immunol. 2016, 77, 791-799. [CrossRef] [PubMed]

22. Rebmann, V.; Konig, L.; Nardi Fda, S.; Wagner, B.; Manvailer, L.F.; Horn, P.A. The Potential of HLA-G-Bearing Extracellular Vesicles as a Future Element in HLA-G Immune Biology. Front. Immunol. 2016, 7, 173. [CrossRef] [PubMed]

23. Paul, P.; Rouas-Freiss, N.; Khalil-Daher, I.; Moreau, P.; Riteau, B.; Le Gal, F.A.; Avril, M.F.; Dausset, J.; Guillet, J.G.; Carosella, E.D. HLA-G expression in melanoma: A way for tumor cells to escape from immunosurveillance. Proc. Natl. Acad. Sci. USA 1998, 95, 4510-4515. [CrossRef] [PubMed]

24. Carosella, E.D.; Paul, P.; Moreau, P.; Rouas-Freiss, N. HLA-G and HLA-E: Fundamental and pathophysiological aspects. Immunol. Today 2000, 21, 532-534. [CrossRef]

25. Park, G.M.; Lee, S.; Park, B.; Kim, E.; Shin, J.; Cho, K.; Ahn, K. Soluble HLA-G generated by proteolytic shedding inhibits NK-mediated cell lysis. Biochem. Biophys. Res. Commun. 2004, 313, 606-611. [CrossRef] [PubMed]

26. Rebmann, V.; LeMaoult, J.; Rouas-Freiss, N.; Carosella, E.D.; Grosse-Wilde, H. Quantification and identification of soluble HLA-G isoforms. Tissue Antigens 2007, 69, 143-149. [CrossRef] [PubMed]

27. Carosella, E.D.; HoWangYin, K.Y.; Favier, B.; LeMaoult, J. HLA-G-dependent suppressor cells: Diverse by nature, function, and significance. Hum. Immunol. 2008, 69, 700-707. [CrossRef]

28. Gonzalez, A.; Rebmann, V.; LeMaoult, J.; Horn, P.A.; Carosella, E.D.; Alegre, E. The immunosuppressive molecule HLA-G and its clinical implications. Crit. Rev. Clin. Lab. Sci. 2012, 49, 63-84. [CrossRef]

29. Carosella, E.D.; Moreau, P.; Lemaoult, J.; Rouas-Freiss, N. HLA-G: From biology to clinical benefits. Trends Immunol. 2008, 29, 125-132. [CrossRef]

30. Carosella, E.D.; Favier, B.; Rouas-Freiss, N.; Moreau, P.; Lemaoult, J. Beyond the increasing complexity of the immunomodulatory HLA-G molecule. Blood 2008, 111, 4862-4870. [CrossRef]

31. Rouas-Freiss, N.; Moreau, P.; LeMaoult, J.; Carosella, E.D. The dual role of HLA-G in cancer. J. Immunol. Res. 2014, 2014, 359748. [CrossRef] [PubMed] 
32. Rutten, M.J.; Dijk, F.; Savci-Heijink, C.D.; Buist, M.R.; Kenter, G.G.; van de Vijver, M.J.; Jordanova, E.S. HLA-G expression is an independent predictor for improved survival in high grade ovarian carcinomas. J. Immunol. Res. 2014, 2014, 274584. [CrossRef]

33. Schwich, E.; Rebmann, V.; Michita, R.T.; Rohn, H.; Voncken, J.W.; Horn, P.A.; Kimmig, R.; Kasimir-Bauer, S.; Buderath, P. HLA-G 3' untranslated region variants $+3187 \mathrm{G} / \mathrm{G},+3196 \mathrm{G} / \mathrm{G}$ and $+3035 \mathrm{~T}$ define diametrical clinical status and disease outcome in epithelial ovarian cancer. Sci. Rep. 2019, 9, 5407. [CrossRef] [PubMed]

34. Thery, C.; Witwer, K.W.; Aikawa, E.; Alcaraz, M.J.; Anderson, J.D.; Andriantsitohaina, R.; Antoniou, A.; Arab, T.; Archer, F.; Atkin-Smith, G.K.; et al. Minimal information for studies of extracellular vesicles 2018 (MISEV2018): A position statement of the International Society for Extracellular Vesicles and update of the MISEV2014 guidelines. J. Extracell Vesicles 2018, 7, 1535750. [CrossRef]

35. Amiot, L.; Ferrone, S.; Grosse-Wilde, H.; Seliger, B. Biology of HLA-G in cancer: A candidate molecule for therapeutic intervention? Cell. Mol. Life Sci. 2011, 68, 417-431. [CrossRef] [PubMed]

36. Jung, Y.W.; Kim, Y.T.; Kim, S.W.; Kim, S.; Kim, J.H.; Cho, N.H.; Kim, J.W. Correlation of human leukocyte antigen-G (HLA-G) expression and disease progression in epithelial ovarian cancer. Reprod. Sci. 2009, 16, 1103-1111. [CrossRef]

37. Rebmann, V.; Regel, J.; Stolke, D.; Grosse-Wilde, H. Secretion of sHLA-G molecules in malignancies. Semin. Cancer Biol. 2003, 13, 371-377. [CrossRef]

38. Rebmann, V.; Busemann, A.; Lindemann, M.; Grosse-Wilde, H. Detection of HLA-G5 secreting cells. Hum. Immunol. 2003, 64, 1017-1024. [CrossRef]

39. Mohme, M.; Riethdorf, S.; Pantel, K. Circulating and disseminated tumour cells-Mechanisms of immune surveillance and escape. Nat. Rev. Clin. Oncol. 2017, 14, 155-167. [CrossRef]

40. Grange, C.; Tapparo, M.; Tritta, S.; Deregibus, M.C.; Battaglia, A.; Gontero, P.; Frea, B.; Camussi, G. Role of HLA-G and extracellular vesicles in renal cancer stem cell-induced inhibition of dendritic cell differentiation. BMC Cancer 2015, 15, 1009. [CrossRef]

41. Dotan, E.; Alpaugh, R.K.; Ruth, K.; Negin, B.P.; Denlinger, C.S.; Hall, M.J.; Astsaturov, I.; McAleer, C.; Fittipaldi, P.; Thrash-Bingham, C.; et al. Prognostic Significance of MUC-1 in Circulating Tumor Cells in Patients With Metastatic Pancreatic Adenocarcinoma. Pancreas 2016, 45, 1131-1135. [CrossRef] [PubMed]

42. Schulze, K.; Gasch, C.; Staufer, K.; Nashan, B.; Lohse, A.W.; Pantel, K.; Riethdorf, S.; Wege, H. Presence of EpCAM-positive circulating tumor cells as biomarker for systemic disease strongly correlates to survival in patients with hepatocellular carcinoma. Int. J. Cancer 2013, 133, 2165-2171. [CrossRef] [PubMed]

43. Grabowskil, J.P.; Mardas, M.; Markowska, A.; Markowska, J. Evaluation of residual tumor locations in advanced ovarian cancer patients after incomplete primary cytoreduction. Eur. J. Gynaecol. Oncol. 2015, 36, 274-277. [PubMed]

44. Wimberger, P.; Heubner, M.; Lindhofer, H.; Jager, M.; Kimmig, R.; Kasimir-Bauer, S. Influence of catumaxomab on tumor cells in bone marrow and blood in ovarian cancer. Anticancer Res. 2009, 29, 1787-1791. [PubMed]

45. Kuhlmann, J.D.; Wimberger, P.; Bankfalvi, A.; Keller, T.; Scholer, S.; Aktas, B.; Buderath, P.; Hauch, S.; Otterbach, F.; Kimmig, R.; et al. ERCC1-positive circulating tumor cells in the blood of ovarian cancer patients as a predictive biomarker for platinum resistance. Clin. Chem. 2014, 60, 1282-1289. [CrossRef] [PubMed]

46. Sokolova, V.; Ludwig, A.K.; Hornung, S.; Rotan, O.; Horn, P.A.; Epple, M.; Giebel, B. Characterisation of exosomes derived from human cells by nanoparticle tracking analysis and scanning electron microscopy. Colloids Surf. B Biointerfaces 2011, 87, 146-150. [CrossRef] [PubMed]

47. Rebmann, V.; Lemaoult, J.; Rouas-Freiss, N.; Carosella, E.D.; Grosse-Wilde, H. Report of the Wet Workshop for Quantification of Soluble HLA-G in Essen, 2004. Hum. Immunol. 2005, 66, 853-863. [CrossRef]

48. Celik, A.A.; Simper, G.S.; Huyton, T.; Blasczyk, R.; Bade-Doding, C. HLA-G mediated immune regulation is impaired by a single amino acid exchange in the alpha 2 domain. Hum. Immunol. 2018, 79, 453-462. [CrossRef]

(C) 2019 by the authors. Licensee MDPI, Basel, Switzerland. This article is an open access article distributed under the terms and conditions of the Creative Commons Attribution (CC BY) license (http://creativecommons.org/licenses/by/4.0/). 